\title{
APLICAÇÃO DA PESQUISA OPERACIONAL AVALIAÇÃO DE FORMULAÇÕES DE RAÇÃO PARA BOVINOS EM CONFINAMENTO UTILIZANDO O SOFTWARE LINGO
}

\author{
Camila Pires Cremasco Gabriel ${ }^{1}$ \\ Luís Roberto Almeida Gabriel Filho² \\ Daniel dos Santos Viais Neto ${ }^{3}$
}

RESUMO: O presente trabalho busca apresentar um método de balanceamento de ração (estudo de caso) que ofereça as exigências necessárias para o desenvolvimento de animais ruminantes, com diversas fontes de proteínas ao custo mínimo de produção para os produtores. Deste modo, o confinamento tem surgido como uma importante ferramenta para o pecuarista, que deseja ganhar em escala no seu sistema de produção e qualidade em seus produtos. Assim, a adoção de técnicas de manejo e alimentação que viabilizem a produção de carnes de melhor qualidade torna-se muito importante para colocar o setor pecuário em situação de igualdade com os grandes países produtores de carne. Para a realização deste trabalho, foi feito um levantamento bibliográfico e uma pesquisa de campo com o administrador de uma fazenda no município de Presidente Prudente-SP. Através dos resultados obtidos, pode-se verificar que neste estabelecimento têm diminuído seus lucros, principalmente em virtude dos altos custos da alimentação.

Palavras-chave: Pecuária. Confinamento. Gado de corte. Software Lingo, Presidente Prudente.

\footnotetext{
${ }^{1}$ Licenciada em Matemática (FCT/UNESP), Mestre em Matemática Pura (DM/UFSCar), Doutora em Agronomia/Energia na Agricultura (FCA/UNESP) e Pós-doutora em Bioestatística (IB/UNESP), Professora Assistente da FATEC - Presidente Prudente. camila@fatecpp.edu.br.

${ }^{2}$ Licenciado em Matemática (FCT/UNESP), Mestre em Matemática Pura (ICMC/USP), Doutor em Agronomia/Energia na Agricultura (FCA/UNESP) e Pós-doutor em Agronomia/Energia na Agricultura (FCA/UNESP), Professor Assistente Doutor da CET/UNESP - Tupã/SP. gabrielfilho@tupa.unesp.br. ${ }^{3}$ Licenciado e Bacharel em Matemática (ICMC/USP), Mestre em Matemática Pura (ICMC/USP), Professor Associado da FATEC - Presidente Prudente. dvneto@fatecpp.edu.br.
} 


\section{INTRODUÇÃO}

A cadeia produtiva da carne tem sido um esteio de sustentação da economia nacional. Uma pesquisa recente realizada pela USDA em abril de 2011, demonstrou que o rebanho mundial de gado encerrou o ano de $2010 \mathrm{com}$ um total de pouco mais de um bilhão de cabeças de gado, representando uma estabilização, equiparando-se com 2009. O Brasil possui o segundo maior rebanho comercial do mundo com 185,1 milhões de cabeças de gado em 2010, segundo USDA 4 .

No Brasil, a bovinocultura de corte é baseada no uso de pastagens, o que resulta na produção de carne de menor custo. Entretanto, devido à sazonalidade na produção de forragem ao longo do ano, os índices zootécnicos da atividade no país ainda estão aquém aos de países de clima temperado.

Os baixos índices de produtividade podem, em parte, ser explicados pela pequena parcela de produtores que utilizam qualquer tipo de suplementação durante todo o processo produtivo e, segundo Lana (2005), no máximo 1,3\% da carne bovina brasileira é produzida pelo uso de ração ou suplemento concentrado durante a fase de terminação.

Diante disso, o confinamento é uma estratégia de alimentação do rebanho que traz os seguintes benefícios: promove o aumento no número de bovinos terminados anualmente, pois libera pastagens para outras categorias animais, reduz a idade de abate, permite a obtenção de carcaças de maior qualidade e aumenta o giro de capital na propriedade.

No passado, a utilização do confinamento tinha como objetivo explorar o acentuado diferencial de preços da entressafra, que atingia em valores reais um acréscimo de $30 \%$, e devido abundância de bois magros no inicio da seca (HADDAD, 2007).

O confinamento deve ser entendido como ferramenta para o manejo da propriedade e de suas pastagens, pois sua utilização como atividade exclusiva pode apresentar baixa rentabilidade, o que pode ser confirmado pelo fato de que terminadores exclusivos representam apenas $12 \%$ dos confinamentos (SIQUEIRA; BERNARDES; SIGNORETTI, 2007). Para os frigoríficos do Brasil central, onde a seca prolongada

${ }^{4}$ Dados disponível em: http://www.mzweb.com.br/minerva/.../conteudo pt.asp 
acarreta grandes dificuldades para obtenção de animais com grau de acabamento adequado, o confinamento como atividade exclusiva pode ser vantajoso.

Outro importante benefício do confinamento para o Brasil seria o aumento do peso de abate que, segundo Lanna e Almeida (2005), encontram-se entre os mais baixos do mundo e impede o país de fornecer carne a mercados como: Japão, Coréia do Sul, Estados Unidos, Canadá e México, que chegam a pagar por novilhos com alto grau de acabamento valores bastante superiores aos recebidos pelos produtores brasileiros.

Entretanto, devido à existência de nichos de mercado para carne magra, produzida exclusivamente a pasto, e a baixa bonificação por qualidade repassada pelos frigoríficos, muitos produtores preferem produzir carne de bovinos inteiros e com baixo grau de acabamento.

O fornecimento de alimentos é um dos fatores de maior importância em sistemas de produção de bovinos, principalmente em situações onde os animais se encontram confinados, pois a alimentação representa o principal custo. Para o balanceamento de dietas e o estabelecimento do manejo da alimentação é fundamental ter conhecimento sobre o consumo voluntário médio dos animais. Estimando o consumo, consegue-se aplicar as exigências nutricionais das várias categorias animais a um desempenho diário esperado e podem-se fazer inferências para avaliar até que ponto os diferentes alimentos utilizados são capazes de suprir essas necessidades, permitindo uma alimentação econômica e nutricionalmente correta (OLIVEIRA et al., 2003).

Além da importância de ter informações sobre o consumo de alimentos pelos animais, é imprescindível conhecer a eficiência de utilização dos alimentos, que pode ser alcançada por diferentes estratégias nutricionais, utilização de raças mais adaptadas e produtivas e, ainda, com processos de melhoramento que permitam selecionar animais de mesma raça mais eficientes no aproveitamento dos alimentos.

Neste contexto, o presente trabalho busca apresentar uma análise do balanceamento de ração que ofereça as exigências necessárias para o desenvolvimento de animais ruminante, com diversas fontes de proteínas ao custo mínimo de produção para os produtores.

\section{METODOLOGIA}


Para atender os objetivos propostos por este trabalho, primeiramente foi realizado pesquisas bibliográficas relacionadas ao tema; em um segundo momento, foi realizado um estudo de caso, por meio de uma entrevista com o administrador de uma fazenda no município de Presidente Prudente para saber a viabilidade econômica do gado confinado.

Para a coleta de dados, foram utilizadas entrevistas, previamente marcadas e autorizadas pelos entrevistados para sua divulgação.

Quanto à técnica utilizada para a entrevista, foi utilizado um questionário contendo questões abertas.

\section{RESULTADOS E DISCUSSÃO}

De acordo com os dados obtidos com o administrador, a propriedade tem 968ha, sendo utilizado para confinamento 1,5 Alqueire.

A fazenda possui duas mil cabeças de gado, das raças nelore, cruzado e mestiços. No confinamento existem 1.500 cabeças, mas a estrutura suporta quatro mil cabeças.

Existem 38 piquetes para o confinamento (sendo 60mx30m), com 100 cabeças de gado, não existindo rotatividade. Quando entra na manga (piquete) fica lá até sair, só no tempo da chuva que tira de um piquete caso estiver alagada e muito barro, então o gado fica no piquete do momento que chega até o final, ninguém vai incomodar durante os 90 dias.

Existe uma caixa d'água com 10 mil litros (bebedouro) para cada dois piquetes e o comedouro é na a proporção dos piquetes, sendo que no caso da fazenda pesquisada é de 60 metros.

Para o fornecimento da ração é utilizado o caminhão misturador.

Não existe fabrica própria de ração. O fornecimento é conforme a dieta passada pelo zootecnista e a matéria-prima utilizada é a mais barata no mercado.

As tabelas 1, 2, 3 e 4 mostram o preço de alguns componentes da ração fabricada para estes bovinos neste período.

Tabela 1: Preço do milho durante o ano de 2011. 


\begin{tabular}{cccc}
\hline Produto & Mês & Ano & Preços/sc.60 kg \\
\hline Milho Amarelo & 1 & 2011 & 26,9 \\
Milho Amarelo & 2 & 2011 & 29,46 \\
Milho Amarelo & 3 & 2011 & 29,25 \\
Milho Amarelo & 4 & 2011 & 28,03 \\
Milho Amarelo & 5 & 2011 & 26,98 \\
Milho Amarelo & 6 & 2011 & 28,53 \\
Milho Amarelo & 7 & 2011 & 28,06 \\
Milho Amarelo & 8 & 2011 & 27,69 \\
Milho Amarelo & 9 & 2011 & 28,75 \\
Milho Amarelo & 10 & 2011 & 27,91 \\
Milho Amarelo & 11 & 2011 & 27,57 \\
Milho Amarelo & 12 & 2011 & 25,16 \\
\hline
\end{tabular}

Fonte: IEA

Tabela 2. Preço da soja durante o ano de 2011.

\begin{tabular}{cccc}
\hline Produto & Mês & Ano & Preços/sc.60 kg \\
\hline Soja & 1 & 2011 & 50,53 \\
Soja & 2 & 2011 & 48,91 \\
Soja & 3 & 2011 & 45,46 \\
Soja & 4 & 2011 & 43,19 \\
Soja & 5 & 2011 & 43,91 \\
Soja & 6 & 2011 & 44,29 \\
Soja & 7 & 2011 & 43,67 \\
Soja & 8 & 2011 & 44,98 \\
Soja & 9 & 2011 & 47,92 \\
Soja & 10 & 2011 & 47,04 \\
Soja & 11 & 2011 & 45,18 \\
Soja & 12 & 2011 & 44,13 \\
\hline
\end{tabular}

Fonte: IEA

Tabela 3. Preço do farelo de algodão durante o ano de 2011.

\begin{tabular}{cccc}
\hline Produto & Mês & Ano & Preços/ton \\
\hline Farelo de algodão & 1 & 2011 & 590 \\
Farelo de algodão & 2 & 2011 & 610 \\
Farelo de algodão & 3 & 2011 & 590 \\
Farelo de algodão & 4 & 2011 & 590 \\
Farelo de algodão & 5 & 2011 & 580 \\
\hline
\end{tabular}




\begin{tabular}{lccc} 
Farelo de algodão & 6 & 2011 & 590 \\
Farelo de algodão & 7 & 2011 & 540 \\
Farelo de algodão & 8 & 2011 & 540 \\
Farelo de algodão & 9 & 2011 & 550 \\
Farelo de algodão & 10 & 2011 & 540 \\
Farelo de algodão & 11 & 2011 & 550 \\
Farelo de algodão & 12 & 2011 & 520 \\
\hline
\end{tabular}

Fonte: IEA

Tabela 4. Preço do sorgo durante o ano de 2011.

\begin{tabular}{cccll}
\hline Produto & Mês & Ano & Preços/sc.60 kg & \\
\hline Sorgo & 1 & 2011 & $\mathrm{R} \$$ & 17,19 \\
Sorgo & 2 & 2011 & $\mathrm{R} \$$ & 16,35 \\
Sorgo & 3 & 2011 & $\mathrm{R} \$$ & 15,59 \\
Sorgo & 4 & 2011 & $\mathrm{R} \$$ & 15,45 \\
Sorgo & 5 & 2011 & $\mathrm{R} \$$ & 15,54 \\
Sorgo & 6 & 2011 & $\mathrm{R} \$$ & 16,12 \\
Sorgo & 7 & 2011 & $\mathrm{R} \$$ & 17,49 \\
Sorgo & 8 & 2011 & $\mathrm{R} \$$ & 18,49 \\
Sorgo & 9 & 2011 & $\mathrm{R} \$$ & 18,90 \\
Sorgo & 10 & 2011 & $\mathrm{R} \$$ & 17,40 \\
Sorgo & 11 & 2011 & $\mathrm{R} \$$ & 16,62 \\
Sorgo & 12 & 2011 & $\mathrm{R} \$$ & 17,38 \\
\hline
\end{tabular}

Fonte: IEA

De acordo com o administrador, no confinamento não existe lucro. O custobenefício é adiantar o gado em um ano praticamente para o abate.

O armazenamento da matéria-prima é feito em silos para armazenar milho, soja, núcleo etc.

$\mathrm{Na}$ fazenda existem 4 silos, de mais ou menos 10 metros por 45 metros.

É utilizada uma parte da propriedade para plantar a cana que é usada para fazer a silagem. O investimento é de 70,00 reais por tonelada, já incluso todos os gastos de produção.

Os animais utilizados para confinamento são: nelore, cruzado e mestiço. Os animais vêm de outras fazendas do mesmo grupo espalhadas pelo Mato Grosso do Sul, sendo sua maioria macho, ou seja, $98 \%$ e $2 \%$ fêmeas de descartes, com idades que variam de 24 meses acima, com o peso de $360 \mathrm{~kg}$. 
Este animal fica apenas 90 dias no confinamento, saindo com 27 meses ou mais para o abate.

Seu peso varia de acordo com o peso de entrada. Geralmente, o animal, tem ganhado de peso de $1,2 \mathrm{~kg}$ a $1,4 \mathrm{~kg}$ por dia.

Para sua alimentação são fornecidas, silagem de cana, o milho, soja e o núcleo. As quantidades são orientadas pelo zootecnista. Segundo o administrador, "na entrada do animal, que é a fase de adaptação, ele come $0,8 \%$ do peso dele. Então se tenho um animal com $360 \mathrm{~kg}$ vai comer $2,880 \mathrm{~kg}$ de ração esse período é de 13 dias a partir do $13^{\circ}$ dia $1,2 \%$ do peso que seria de 4,320kg de ração até chegar a 2,0\% peso que seria $7,200 \mathrm{~kg}$ de ração isso por dia agora a silagem seria a vontade, como não tem valor nutritivo serve só para encher a barriga do animal. Ele ganha peso com a ração".

Cada lote possui 100 cabeças de gado, sendo que seu custo é de 6,00 reais por cabeça/dia.

Neste trabalho apenas foi considerado o custo com ração diária.

Inicialmente consideramos uma solução unitária que gerou o seguinte resultado, considerando $\mathrm{x} 1$ milho, $\mathrm{x} 2$ soja, $\mathrm{x} 3$ farelo de algodão e $\mathrm{x} 4$ sorgo. Suas disponibilidades constam na última coluna durante os noventa dias considerados. O custo nesta solução é de 684,62 reais, como mostra a tabela 5 .

Tabela 5. Solução unitária.

\begin{tabular}{crrrrrr}
\hline x1 & 60 & & & & 60 & 6000 \\
\hline x2 & & 60 & & & 60 & 6000 \\
x3 & & & 1 & & 1 & 1,5 \\
x4 & & & & 60 & 60 & 6000 \\
& & & & & & \\
Custo & 26,9 & 50,53 & 590 & 17,19 & & \\
Unitário & 1 & 1 & 1 & 1 & & 684,62 \\
\hline
\end{tabular}

A tabela 6,7 e 8 é apresentada as soluções dos meses de janeiro, fevereiro e março. 
Tabela 6. Solução do mês de janeiro de 2011.

\begin{tabular}{rrrrr}
\hline 60 & & & 60 & 6000 \\
\hline 60 & & & 6000 & 6000 \\
& 1 & & 1,5 & 1,5 \\
& & 60 & 6000 & 6000
\end{tabular}

A tabela 6 mostra que o custo em ração foi de $R \$ 9889,70$, onde foram necessários 83 sacas de milho, 100 sacas de soja uma tonelada e meia de farelo de algodão e 100 sacos de sorgo. Da disponibilidade foram utilizada as todos os componentes completamente com exceção dos sacos de milho.

A tabela 7 mostra que o custo da ração em fevereiro foi de $\mathrm{R} \$ 9090,76$, onde foram necessárias 56 sacas de milho, 100 sacas de soja uma tonelada e meia de farelo de algodão e 100 sacos de sorgo. Da disponibilidade foram utilizados a todos os componentes completamente com exceção dos sacos de milho.

Tabela 7. Solução de fevereiro de 2011.

\begin{tabular}{rrrrrr}
\hline 60 & & & & 60 & 6000 \\
& 60 & & & 6000 & 6000 \\
& & 1 & & 1,5 & 1,5 \\
& & & 60 & 6000 & 6000 \\
& & & & & \\
29,46 & 48,91 & 610 & 16,35 & & \\
56 & 100 & 1,5 & 100 & & 9090,76 \\
\hline
\end{tabular}


Tabela 8. Solução do mês de março.

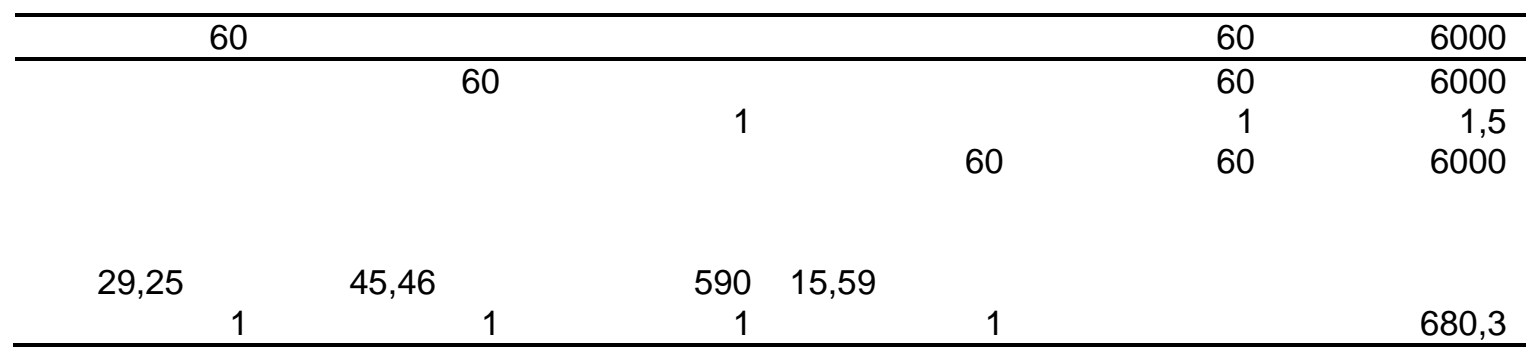

Atualmente, a pecuária de corte tem exigido que os pecuaristas e profissionais da área descubram alternativas para que os sistemas de produção sejam mais competitivos.

Assim, através do presente estudo, pode-se verificar que o confinamento tem se destacado como uma estratégia de alimentação para o gado de corte, que além de reduzir a idade de abate do animal, propicia a obtenção de carcaças de maior qualidade, aumentando assim, o giro de capital na propriedade.

No entanto, de acordo com a pesquisa realizada na fazenda, foi constatado que atualmente o pecuarista não tem tido nenhum lucro com o confinamento do gado, em comparação com o mesmo período, no ano de 2011. O pecuarista tem apenas o adiantamento do abate.

Pode-se dizer que nos meses de março a junho com o custo de alguns componentes mais baixo a ração bem mais acessível que em outros meses como janeiro, fevereiro.

\section{CONCLUSÃO}

Concluindo todas as análises foi verificado que nos meses de janeiro, fevereiro, março, junho e julho a melhor opção é o consumo total de todos os componentes, sendo a exceção o milho. Já nos meses complementares ocorre um custo maior dos componentes de farelo e sorgo sendo necessário aumentar o consumo de milho e soja. 


\section{REFERÊNCIAS}

HADDAD, C. M. Requisitos de qualidade na bovinocultura de corte. SIMPÓSIO SOBRE BOVINOCULTURA DE CORTE, 6., 2007, Piracicaba, SP. Anais... Piracicaba: ESALQ, 2007.

LANA, R. P. Nutrição e alimentação animal: mitos e realidades. Viçosa: UFV, 2005. 343 p.

LANNA, D. P. D.; ALMEIDA, R. A terminação de bovinos em confinamento. Visão Agrícola, Piracicaba, v. 3, p. 55-58, ago. 2005.

OLIVEIRA, R. F. M.; FONTES, C. A. A.; GOMIDE, J. A.; SILVA, J. P. C.; PAULINO, M. F. Consumo e digestibil idade de dietas com duas proporções de concentrados em bovinos de três grupos genéticos. Revista da Sociedade Brasileira de Zootecnia, Viçosa, v. 20, n. 5, p. 513-521, 2003.

SIQUEIRA, G.; BERNARDES, T. F.; SIGNORETTI, R. D. A produção de volumosos conservados como componente do sistema de produção de bovinos de corte. In:

SIMPÓSIO DE PECUÁRIA DE CORTE: ALTERNATIVAS PARA OS NOVOS DESAFIOS, 5., 2007, Lavras, MG. Anais... Lavras: UFLA/NEPEC, 2007. p. 165-227. 